Journal of Southeast Asian

2015

\title{
Kawm Ntawv Qib Siab Understanding the psychosociocultural educational experiences of Hmong American undergraduates
}

Mariko M. Lin

University of Oregon

Pa Her

University of Wisconsin - Madison, her1@wisc.edu

Alberta M. Gloria

University of Wisconsin-Madison

Follow this and additional works at: https://docs.lib.purdue.edu/jsaaea

\section{Recommended Citation}

Lin, Mariko M.; Her, Pa; and Gloria, Alberta M. (2015) "Kawm Ntawv Qib Siab Understanding the psychosociocultural educational experiences of Hmong American undergraduates," Journal of Southeast Asian American Education and Advancement: Vol. 10 : Iss. 1, Article 7.

DOI: $10.7771 / 2153-8999.1123$

Available at: https://docs.lib.purdue.edu/jsaaea/vol10/iss1/7

This document has been made available through Purdue e-Pubs, a service of the Purdue University Libraries. Please contact epubs@purdue.edu for additional information.

This is an Open Access journal. This means that it uses a funding model that does not charge readers or their institutions for access. Readers may freely read, download, copy, distribute, print, search, or link to the full texts of articles. This journal is covered under the CC BY-NC-ND license. 


\section{Kawm Ntawv Qib Siab Understanding the psychosociocultural educational experiences of Hmong American undergraduates}

\section{Cover Page Footnote}

Author Notes. Kawm Ntawv Siab (Hmong in Higher Education). Mariko M. Lin is a senior staff psychologist at the University of Oregon University Counseling and Testing Center. Pa Her is a doctoral student and Alberta M. Gloria is a Professor in the Department of Counseling Psychology at the University of Wisconsin-Madison. This article is based on the first author's master's thesis conducted under the supervision of the third author. Correspondence concerning this article should be addressed to Pa Her, Department of Counseling Psychology, University of Wisconsin-Madison, School of Education, 335 Education Building - 1000 Bascom Mall, Madison, WI 53706-1326 (email: her1@wisc.edu). 


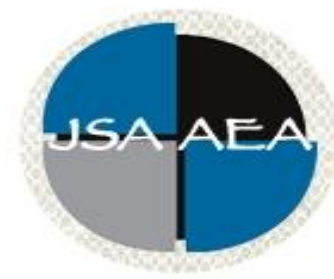

Volume 10 (2015)

\title{
Journal of Southeast Asian American Education and Advancement
}

\author{
www.JSAAEA.org \\ Kawm Ntawv Qib Siab: \\ Understanding the Psychosociocultural Educational Experiences \\ of Hmong American Undergraduates \\ Mariko M. Lin \\ University of Oregon \\ Pa Her \\ University of Wisconsin-Madison
}

Alberta M. Gloria

University of Wisconsin-Madison

\begin{abstract}
Using a psychosociocultural framework, this study examined the educational experiences of 85 Hmong American undergraduates attending a predominantly-White university. Differences in class standing indicated that upper-division students reported higher confidence in college-related tasks than their lower-division counterparts, yet the upperdivision students perceived a less-welcoming university environment that was incongruent with their cultural values than the lower-division undergraduates. Peer support, college self-efficacy and cultural congruity were salient variables in understanding Hmong American undergraduate's educational experiences. The study's limitations, future research directions, and implications for college administrators and faculty are discussed.
\end{abstract}

\section{Introduction}

Although Asian Americans have higher educational attainment than other racial groups in the U.S. (U.S. Census, 2013), not all Asian Americans are academically successful. A bimodal distribution exists as many Southeast Asian refugees have lower academic achievement and higher rates of high school dropouts as compared to other Asian groups (Chiang, Fisher, Collins, \& Ting, 2015; Fuertes, Sedlacek, \& Liu, 1994; Hsia \& Hirano-Nakanishi, 1996; Tang, Kim, \& Haviland, 2013). For those who have a lower pre-migration education and less academic and economic capital, educational attainment is also increasingly disproportionate (Chiang et al., 2015; Xiong, 2012). For instance, Hmong individuals migrated to the U.S. when they fled their native homeland due to political and socio-historical factors in the 1970s (Xiong, 2012). With little contact with modern, industrialized cultures, many Hmong people were slash-and-burn farmers and had limited opportunities for formal education (Millett, 2002). 
As a small (i.e., less than 250,000) but rapidly-growing population, more than $40 \%$ of the current U.S. Hmong population is under the age of 18 (U.S. Census, 2013) and the first in their families to attend college. In particular, Hmong Americans maintain the highest percentage of under-education $(59.6 \%$ have a high school diploma or less) than any other Asian ethnic group (19.6\% have high school diploma or less) (Reeves \& Bennett, 2004). Specifically, only 12.5\% have completed a bachelor's degree and only $3.1 \%$ have a graduate or professional degree (U.S. Census 2013; Xiong, 2012). Despite low educational attainments, many Hmong families and communities value the role and function of a higher education for their children as a means of economic and social mobility (Lee, 2007).

Within higher education, Hmong American undergraduates are considered an "at-risk" population given their lower levels of educational success (Su, Lee, \& Vang, 2005; Swartz, Lee, \& Mortimer, 2003). Research suggests that their under-education is due to factors such as truancy, dropout rates, delinquency (e.g., gang activity), limited financial resources, low parental education, and cultural values that are infrequently reflected in higher education (Lee, 2001; Su et al., 2005; Swartz et al., 2003; Xiong \& Lam, 2013). As Hmong American students increasingly access higher levels of education, a fuller understanding of their educational and academic persistence processes is warranted.

Within the literature, the academic performance of Hmong Americans is equivocal. Some research indicates that Hmong Americans do not perform well (e.g., Lee, 2001; Reeves \& Bennett, 2004), yet two longitudinal studies indicated that their academic achievement is comparable or better than non-Hmong populations (Hutchinson, 1997; Swartz et al., 2003). These studies revealed that Hmong American students had higher levels of retention and educational attainment (e.g., earning a bachelor's degree) than all other racial/ethnic groups within a Midwestern university system. The divergence of findings may in part be due to participants differing in educational age groups (i.e., high school versus college) and noncomparable sample groups (i.e., census data versus a qualitative study with an unspecified sample size).

Despite reports of increased academic success, there remains a need to understand the educational experiences of Hmong American undergraduates to maintain and facilitate their academic persistence (i.e., a student's choice to stay in school, Pascarella \& Terenzini, 1980). Previous literature on Hmong American undergraduates serves as a critical foundation for this study, yet it is limited by descriptive overviews of educational attainment (Hutchinson, 1997; Xiong, 2012), the use of undergraduate samples without explicit examination of their educational processes (Lor, 2008; Su et al., 2005), and a focus on high school-aged participants (Lee, 2001; McNall, Dunnigan, \& Mortimer, 1994). Further, the research on Hmong American students has focused on cognitive factors such as time spent studying and school dropout rate (McNall et al., 1994) as well as attainment (Swartz et al., 2003), indices which may not fully explain students' educational experiences (Suzuki, 1994).

Unlike traditional approaches of student development that attend to students' cognitive factors (e.g., grade point average, credits to graduation) and educational outcomes (e.g., graduation), scholars call for examinations of non-cognitive factors (Castellanos \& Gloria, 2007; Suzuki, 1994) which emphasizes the "whole student" (Canon, 1996) and the varied dimensions of their educational experiences. Thus, a psychosociocultural framework (Gloria \& Rodriguez, 2000), which utilizes a non-cognitive approach in which socio-emotional, personal, and contextual considerations explain students' choices to persist or stay in school (i.e., academic persistence), serves as the basis for this study. Based on literature which implicates self-understanding (Fuertes et al., 1994; Gloria \& Ho, 2003), interconnections (Fass \& Tubman, 2002; Swartz et al., 2003), and cultural context (Chang 2003; Hurtado, 1994) as salient features informing academic persistence, the psychosociocultural approach addresses the dynamic and interdependent relationships of psychological, social, and cultural dimensions for students of colorprocesses central to understanding their ongoing educational experiences and challenges within the university context (Gloria \& Rodriguez, 2000). 
Examining this multifaceted process, previous research (e.g., Castellanos \& Gloria, 2007; Gloria \& Ho, 2003) has supported the three dimensions as salient to the educational experiences of students of color. Designed as a meta-theory, the dimensions (i.e., psychological, social, and cultural) together formulate the holistic framework under which different factors or variables reflect the dimension and population being studied (Castellanos \& Gloria, 2007). The dimensions are interrelated areas of study for students of color in higher education (Castellanos, Gloria, \& Kamimura, 2006), and thus a precept of the psychosociocultural approach is that each dimension will uniquely and collectively predict academic persistence. For this study, the psychological dimension involved self-beliefs (i.e., perfectionism, selfesteem, college self-efficacy, and imposter syndrome), the social dimension addressed perceived social support (i.e., support from mentors, friends and family), and the cultural dimension included individual and academic university comfort (i.e., ethnic identity, cultural congruity, and university perception).

\section{Psychological Dimension - Self-Beliefs}

Defined as how one perceives oneself, self-beliefs have been consistently identified as a significant factor influencing the educational experiences of racial/ethnic minority students (Solberg, O'Brien, Villarreal, Kennel, \& Davis, 1993). For Asian Americans, perceptions of self such as academic self-concept and achievement expectancies were significant predictors of performance (i.e., cumulative grade point average) (Fuertes et al., 1994; House, 1997). A closely-related study on Asian American undergraduates indicated adherence to Asian values positively predicted collective self-esteem, and adherence to European American values positively predicted general self-efficacy (Kim \& Omizo, 2005). As one of the few studies on factors influencing Asian American undergraduates' academic persistence, self-esteem and college self-efficacy (i.e., confidence in one's ability to complete successfully college related tasks) were significant and positive predictors of persistence (Gloria \& Ho, 2003).

As many Hmong American youth are the first in their family to enter college, these students experience inordinate pressure to perform and meet expectations of their parents and Hmong community elders to succeed academically for the purpose of social and economic mobility (Swartz, et al., 2003). For example, many adolescents and young adults are "referred to as 'you young people' (nej cov hluas) and the 'intellectual group' (yog cov txawj ntse) who must 'lead the Hmong to the future' (yuav tsum coj haiv neeg Hmoob lawm yav tom ntej)" (Lee, 2007, p. 5). This phrasing is "demanded by parents, elders, and Hmong leaders as an exhortation to the younger Hmong generations" (Lee, 2007, p. 5). It is thus questioned whether Hmong American students may doubt their ability to meet parental expectations (despite their potential to achieve them), subsequently engendering a sense of excessively high personal standards (i.e., perfectionism; Burns, 1980) or intellectual phoniness (i.e., imposter syndrome; Clance \& Imes, 1978; Langford \& Clance, 1993).

Further, students may also question their ability or have a sense of imposter syndrome if they feel themselves unwelcomed or not "fitting" in to their academic environment (Gloria \& Rodriguez, 2000). Indeed, students' feelings of phoniness extend beyond their cognitive abilities (e.g., grade point average) to their sense or perception of self (Clance \& Imes, 1978; Langford \& Clance, 1993) or even wellness (Cokley, McLain, Enciso, \& Martinez, 2012). For example, King and Cooley (1995) found that undergraduates with a greater orientation toward family achievement had increased levels of feeling like an imposter. Both perfectionism and imposter feelings have yet to be explored fully within the higher educational setting, however these feelings may be evident given their strong family connection (Xiong \& Lam, 2013), educational experiences (Xiong, 2012) perception of parental expectations for success (Supple, McCoy, \& Wang, 2010), and community expectations as first-generation college students (Lee, 1997). 
Only one study to date has quantitatively addressed how familial and community expectations influence self-beliefs, and revealed that intellectual phoniness was the most significant predictor of academic persistence for 103 Hmong American undergraduates (Sengkhammee et al., 2008). Given expectations to advance the family through their own academic success (Lee, 2007; Lor, 2008; Supple et al., 2010; Swartz et al., 2003), it was anticipated that Hmong American undergraduates would question their personal and academic self-esteem, confidence, skills and capability to succeed. This hypothesis would lend explanation as to how self-beliefs might influence academic persistence decisions.

\section{Social Dimension - Social Support}

Social support, a construct important to academic persistence, has also been shown to protect against the alienation and subtle discrimination experienced by racial and ethnic minority students (Delgado-Romero \& Hernandez, 2002). For example, perceived attachment to parents and peers enhances one's sense of self, internal locus of control, self-esteem, and optimism with a multiethnic college sample (Fass \& Tubman, 2002). For Asian American undergraduates, social support was the strongest predictor of academic persistence, with perceived support from friends consistently higher than perceived familial support (Gloria \& Ho, 2003). As a result, Gloria and Ho (2003) emphasized the importance of support from individuals (i.e., fellow students) who have the functional knowledge and skills to manage academics in combination with familial support to enhance Asian American undergraduates' academic persistence.

For many Hmong individuals, the value of community through family (kinship) provides Hmong American students with the strong social support and cultural network that drives their educational pursuits (Hutchinson, 1997; McNall et al., 1994; Moua, 2003). Because many Hmong families, and parents in particular, highly value education (Her \& Gloria, 2015; Hutchinson, 1997), family support and parental expectations to earn a degree and provide familial financial support have been revealed as primary influences in their children's educational attainment (Lee, 1997; Lor, 2008; Swartz et al., 2003). With prescribed gender roles for Hmong females and males (Moua, 2003; McNall, et al., 1994) that influence expectations for education (Her \& Gloria, 2015; Lee, 1997; Ngo, 2002), differences in general educational experiences were anticipated by gender.

The social support of mentorship also plays a critical role in the academic achievement of Hmong American students. For example, in two different qualitative studies (Lor, 2008; Swartz et al., 2003) Hmong students reported that their association with academically-oriented peers inspired them to similarly engage academically and these peers were salient to their educational experiences. Such mentorship is evidenced as upper division Hmong students often serve as role models and "pass on" knowledge to lower division students on how to succeed academically - a process that also occurs between Hmong siblings (Hutchinson, 1997). As first-generation college students navigating unfamiliar academic environments, it is likely that the perceived support received from family and friends will affect their educational experiences.

\section{Cultural Dimension - University Comfort}

A sense of comfort within the university environment is frequently implicated as a critical element to social adjustment, academic resilience (Suzuki, 1994), perceptions of a welcoming environment (Hurtado, 1994), and academic persistence decisions, especially for racial ethnic minorities (House, 1997) and Asian ethnic groups in particular (Gloria \& Ho, 2003). University comfort addresses both the meaning and importance of culture for individuals within the environment (i.e., ethnic identity) and the influence of 
academic culture on the person (e.g., cultural congruity refers to the degree of fit of one's personal values and the values of the university environment, Gloria \& Robinson Kurpius, 1996). For example, perceptions of campus climate differ among racial groups with students of color generally perceiving a more negative campus climate than White students (Chang, 2003; Rankin \& Reason, 2005) as they contend with cumulative effects of racism and discrimination on a day-to-day basis (Sue \& Sue, 2009).

As upper division Hmong American undergraduates held more negative perceptions of the university environment and a decreased level of cultural incongruity, Sengkhammee et al. (2008) suggested that older students were more likely to identify and perceive oppression in their academic lives. Additionally, to manage unwelcoming contexts that frequently occur (Hurtado, 1994), students who hold a strong sense of cultural self (Torres \& Hernandez, 2007) and positive self-concept (Fuertes et al., 1994) were more likely to navigate successfully the university environment. Together, varying perceptions of the university environment, cultural congruity, and ethnic identity among students in different class standings are anticipated.

Ultimately, comfort within the university environment affects Asian American students' social adjustment and academic resilience (Suzuki, 1994), with university perception differing by Asian ethnic group (Gloria \& Ho, 2003). As recent immigrants with strong cultural and familial traditions (Moua, 2003), it was anticipated that Hmong American undergraduates would have a strong sense of ethnic identity, less positive perception of the environment, and lower cultural congruity. Thus, an incongruent cultural fit within the university and or engagement within an unfriendly academic environment would influence Hmong American undergraduates' experiences within their academic context.

Based on the holistic framework of student academic persistence developed by Gloria and Rodriguez (2000), and also extending Gloria and Ho's (2003) work with Asian Americans, this study posed two primary questions to investigate the educational experiences of Hmong American undergraduates. Hypotheses were formulated from the psychosociocultural framework and supporting educational literature on Asian American and Hmong Americans. Based on previous differences within the literature (Gloria, Castellanos, Orozco, 2005; Sengkhammee et al., 2008), the first question asked how psychological, social, and cultural factors differed by gender and class standing (lower and upper division) for Hmong Americans. Per Sengkhammee et al.'s (2008) findings, it was anticipated that females and upper division students would report higher self-beliefs and increased social support. Females were also anticipated to report higher cultural congruity and more positive perceptions of the university environment, as consistent with previous research (Gloria, Hird, \& Navarro, 2001). Further, upper division students were expected to report lower cultural congruity, less positive perceptions of the university environment, and increased levels of ethnic identity (Sengkhammee et al., 2008; Torres \& Hernandez, 2007).

With expected interrelationships between the psychological, social, and cultural dimensions (Gloria \& Rodriguez, 2000) for Hmong American undergraduates, the second research question asked how the three variable sets were interrelated and assessed students' overall educational experiences. It was anticipated that the three dimensions would be significantly and positive correlated, again consonant to the findings with Asian American (Gloria \& Ho, 2003) and Hmong American (Sengkhammee et al., 2008) undergraduates.

A follow-up question was posed to determine which of the study's variables was most predictive of academic persistence decisions. Based on high expectations of educational achievement for Hmong youth as first generation college students (Lee, 2007; Supple et al., 2010; Swartz, et al., 2003), it was anticipated that imposter syndrome would emerge as most predictive of persistence. 


\section{Method}

\section{Student Participants}

Collected as part of a larger study on Asian American undergraduates, 85 Hmong American students participated in the study. A total of 36 males and 49 females were included with $33(38.8 \%)$ freshmen, 17 (20.0\%) sophomores, $26(30.6 \%)$ juniors, and 9 (10.6\%) seniors. Ranging in age from 17 to $23(M=19.33$ years, $S D=1.25)$, the participants reported a mean grade point average of $2.95(S D=.46$, range $=1.60$ to 4.00). Most participants reported that their mothers $(52.9 \%)$ and fathers $(28.2 \%)$ had no formal schooling, and some indicated that their mothers $(15.3 \%)$ and fathers $(27.1 \%)$ had a high school degree or general educational development proficiency. Students financed their education through several means, including their parents $(n=36)$, relatives $(n=4)$, work study programs $(n=39)$, financial aid/scholarships $(n=80)$, student loans $(n=26)$, savings $(n=17)$, personal finances $(n=7)$, and other $(n=2)$. The majority of the students $(n=57,68 \%)$ were first-generation U.S.-born and the remaining participants $(n=9,11 \%)$ were born in their native country and later immigrated to the U.S. A total of 18 (21\%) students did not report this information.

\section{Instrumentation}

The survey took approximately 45 minutes to complete, and consisted of general demographic questions and 11 scales (10 standardized and 1 researcher-developed). Because of the large number of instruments used, only a brief review is provided for each.

\section{Psychological dimension - self-beliefs variable set.}

Perfectionism. The Perfectionism Scale (Burns, 1980) assesses self-oriented perfectionism (10 items). Responses are rated from 1 (strongly disagree) to 5 (strongly agree), with higher scores indicating higher levels of perfectionism. Use of the scale with Japanese male college students revealed adequate internal consistency of .63 (Sumi \& Kanda, 2002).

Self-Esteem. The Rosenberg Self-Esteem Scale (Rosenberg, 1965) measures general feelings of acceptance and self-worth (10 items) rated from 1 (strongly disagree) to 4 (strongly agree). Higher scores indicate increased perceptions of self-worth. Use of the scale with Asian American undergraduates indicated adequate internal consistency of .88 (Lee \& Yoo, 2004).

College Self-Efficacy. The College Self-Efficacy Inventory (Solberg et al., 1993), originallydeveloped for Latino students, examines confidence in one's ability to complete specific college-related tasks. The scale consists of three subscales, of which only course efficacy and social efficacy were used (14 items total). Scores range from 1 (no confidence at all) to 7 (complete confidence). Higher scores reflect a greater level of confidence in completing college-related tasks. Use of the inventory with Asian American undergraduates yielded adequate internal consistency of .82 (Gloria \& Ho, 2003).

Phoniness. The Imposter Syndrome Scale (Harvey, 1982) measures the degree to which individuals experience imposter feelings (14 items). Rated from 1 (not at all true) to 7 (very true), higher scores suggest an increased sense of intellectual phoniness. In a study with diverse college students, a Cronbach's alpha of .82 was reported (Ross, Stewart, Mugge, \& Fultz, 2001).

\section{Social dimension - social support variable set.}

Mentoring. The Mentoring Scale. (Gloria, Robinson Kurpius, Hamilton, \& Willson, 1999) assesses perceived university mentorship. The five items are rated from 1 (strongly disagree) to 4 
Lin et al.: Kawm Ntawv Qib Siab Understanding the psychosociocultural educational experiences of Hmong American undergraduates

Lin, Her, Gloria - Understanding the educational experiences of Hmong American undergraduates

(strongly agree). Previous use with Asian American undergraduates (Gloria \& Ho, 2003) yielded a Cronbach's alpha of .71.

Parental Encouragement. The Parental Educational Encouragement Scale (Gloria et al., 1999) assessed parental encouragement of education. Rated from 1 (strongly disagree) to 4 (strongly agree), increased scores represent higher perception of parental support for education. Use with Latina/o students has yielded adequate internal consistency of 89 (Gloria et al., 2005).

Friend Support. The Perceived Social Support Inventory - Friends (Procidano \& Heller, 1983) measures the extent to which one believes that his/her needs for support, information, and feedback are being met by friends (20 items). Using slightly modified instructions (i.e., asking participants to respond in relation to friends who were also attending college), ratings were based on a 1 (strongly disagree) to 5 (strongly agree) scale. Higher scores reflect an increased perception of support from friends. Use of the scale with Asian American college students yielded adequate internal consistency of .79 (Gloria \& Ho, 2003).

\section{Cultural dimension - university comfort variable set.}

Identity. The Multiethnic Identity Measure (Phinney, 1992) consists of two scales (Ethnic Identity14 items; Other-group Orientation-6 items) and three subscales. Only the ethnic identity scale was used to assess attitudes and sense of belonging. Items are rated from 1 (strongly agree) to 4 (strongly disagree) with higher scores reflecting a more positive ethnic identity. A strong Cronbach's alpha of .90 was revealed for Asian American undergraduates (Lee \& Davis, 2000).

Congruity. The Cultural Congruity Scale (Gloria \& Robinson Kurpius, 1996) measures the degree to which racial/ethnic minority students feel a sense of cultural congruency with the values of the academic environment (13 items). Items (five are reverse-coded) are rated from 1 (not at all) to 7 (a great deal), with higher scores reflective of increased congruency. Use of the scale with Asian American students has yielded a .76 internal consistency (Gloria \& Ho, 2003).

Environment. The University Environment Scale (Gloria \& Robinson Kurpius, 1996) assesses the degree to which students feel welcomed in the college environment (14 items). Rated on a 7-point scale ranging from 1 (not at all true) to 7 (very true), high scores represent a positive perception of the university environment. Adequate internal consistency coefficients of .82 were reported with five Asian American ethnic undergraduate groups (Gloria \& Ho, 2003).

\section{Criterion variable.}

Persistence. The Persistence/Voluntary Dropout Decisions Scale (Pascarella \& Terenzini, 1980) explores the academic persistence decisions of undergraduates. Rated from 1 (strongly disagree) to 5 (strongly agree), this 30-item scale has five subscales (i.e., Peer-Group Interactions, Interactions with Faculty, Faculty Concern for Student Development and Teaching, Academic and Intellectual Development, and Institutional and Goal Commitments). Higher scores on the scale reflect fewer nonpersistence decisions or more positive decisions to stay in school. Adequate internal consistency coefficients of .71 were yielded when used with Asian American undergraduates when used as a total scale score (Gloria \& Ho, 2003).

\section{Study Setting and Procedure.}

This study was conducted at a large public predominantly-White Midwestern university in which five percent of the undergraduate population is Asian American and approximately 250 students are Hmong. After securing appropriate institutional review board approval, students were recruited at ethnicspecific student organization meetings and events Students were also recruited at other central locales 
(e.g., library) and via the non-parametric method of "snowballing." Participants were informed of the study's purpose and their rights as participants. Surveys were returned directly to the researcher (serving as study consent) at the time of distribution. Students were also provided self-addressed envelopes to return their survey via campus mail if needed. Upon return of the survey, students received a pre-paid ticket to the local movie theater as incentive for their participation.

\section{Results}

Adequate internal consistency coefficients were achieved for each scale from .73 to .92. Descriptives and correlations for each of the study's variables are presented in Table 1.

\section{Question 1 - What are the differences by gender and class standing for the study's variables?}

A 2 (gender) X 2 (class standing) multivariate analysis of variance was used to determine the group means differences for the study's variables. Anticipated findings were generally supported as both main effects were significant $\left[\lambda=.74, \mathrm{~F}=2.04, \underline{p}<.05\right.$, eta $^{2}=.26$ and $\lambda=.62, \mathrm{~F}=3.66, \underline{p}<.001$, eta ${ }^{2}=.38$, respectively]. The gender by class standing interaction was not significant $\left[\lambda=.89, p>.05\right.$, eta $\left.{ }^{2}=.11\right]$. By gender, a significant difference was found for friend support $\left[F(1,79)=9.55, \underline{p}<.005\right.$, eta $\left.{ }^{2}=.11\right]$ with females perceiving higher support than their male counterparts $(M=3.85, S D=.64$ and $M=3.45$, $S D=.61$, respectively). By class standing, significant differences were revealed for congruity $[F(1,79)=$ $5.15, p \leq .05$, eta $\left.^{2}=.06\right]$ and environment $\left[F(1,79)=5.72, p \leq .05\right.$, eta $\left.{ }^{2}=.07\right]$. Specifically, lowerdivision students indicated a greater fit between self-values and the values of the academic environment than upper-division students $(M=5.14, S D=.86$ and $M=4.63, S D=.91$, respectively). Also, lowerdivision students $(M=5.05, S D=.66)$ indicated a more positive perception of the university environment than upper-division students $(M=4.67, S D=.73)$. Differences were also found for self-efficacy $[F(1,79)$ $=5.48, p \leq .05$ eta $\left.^{2}=.07\right]$. Upper-division students indicated greater levels of confidence than lowerdivision students in completing college-related tasks $(M=5.20, S D=.93$ and $M=4.78, S D=.86$, respectively). Differences also emerged for friend support $\left[F(1,79)=5.48, p \leq .05\right.$, eta $\left.{ }^{2}=.06\right]$, where upper-division $(M=3.82, S D=.62)$ reported a higher perception of social support from friends than lower-division $(M=3.57, S D=.66)$ students.

\section{Question 2 - What are the relationships of the psychological, social, and cultural variable sets?}

To investigate the linear combination of the emergent factor variable sets (i.e., self-beliefs, social support, and university comfort), canonical correlations were determined the most appropriate analysis (e.g., variables continuous, normalcy of variables) to explore the combination of the variable's relationships (see Table 2). Each of the constructs was operationalized by the variables chosen to represent the observed variables (Cole, Maxwell, Arvey, \& Salas, 1993). The self-beliefs variable set included perfectionism, self-esteem, self-efficacy, and phoniness, whereas the social support variable set included mentoring, encouragement, and friend support. The university comfort variable set consisted of identity, congruity, and environment. The linear combination of one variable set correlated with a linear combination of a second variable set is the canonical covariate. The correlation of the covariates is the canonical correlation and the covariate pair is the canonical root. Specifically, the canonical coefficient indicates the weighting of each scale in each covariate and reflects the degree to which that scale holds meaning for the covariate. The total amount of shared variance among the covariates is the squared canonical correlation of significant roots (Harris, 1985; Stevens, 1986; Weiss, 1972). Each successive 
canonical correlation accounts for less variance than the previously extracted canonical roots in which the highest number of possible roots equals the number of variables in the smallest variable set (Harris, 1985; Stevens, 1986; Weiss, 1972). Three roots were thus possible as each variable set had at least three scales. Given the study's smaller sample size, only the first significant root was presented and interpreted per Stevens (1986) recommendation to ensure accurate interpretation of the findings. That variable sets were examined, the likelihood of Type I error associated with univariate correlations was decreased (Harris, 1985). Canonical roots significant with $\beta$ s close to or above .60 were interpreted.

Results revealed significant relationships between the variable sets. Self-beliefs and friend support were related [canonical correlation $=.72, F(12.00,190.79)=5.28, p \leq .001$ ], with one significant root $(p$ $\leq .001)$. The pattern of coefficients revealed that decreased college self-efficacy beliefs $(-.88)$, increased perceptions of being an imposter (.87), and decreased self-esteem (-.65) were related with decreased friend support (-.96), which accounted for $52 \%$ of the variance.

Next, the coefficient pattern for the self-beliefs and university comfort factors variable sets were significantly related [canonical correlation $=.71, F(12.00,201.37)=5.39, p \leq .001$ ], with two significant roots $(p \leq .001$ and $p \leq .05$, respectively). The first canonical root accounted for $55 \%$ of the variance. The canonical covariate indicated that lower self-esteem (-.87), increased imposter feelings (.93), and decreased college self-efficacy (-.58) were strongly associated with decreased perceptions of ethnic identity (-.77) and cultural congruity between self and the academic environment (-.86).

Finally, the social support and university comfort factors were significantly related [canonical correlation $=.66, F(9.00,182.68)=6.61, p \leq .001]$, with two significant roots $(p \leq .001, p \leq .05)$. The first canonical root accounted for $40 \%$ of the variance of the variable sets. The pattern of coefficients revealed that decreased perception of friend support (-.91) and encouragement from family (-.64) was related to lower ethnic identity (-.91) and cultural congruity between self and the academic environment (.72).

Question 3 - What is the strongest predictor of academic persistence decisions?

Posed as a follow-up question, a stepwise regression was conducted to determine which of the study's individual variables was most predictive of academic persistence. Important to note is that statistical packages correctly identify the best single predictor via a stepwise regression, yet incorrectly compute the degrees of freedom as subsequently variables are added (Thompson, 1995). Three of the ten study's variables (i.e., phoniness, congruity, and friend support) were entered into the omnibus equation $[F(1,78)$ $=54.69, p \leq .001]$. As expected, phoniness emerged as the strongest predictor $(42 \%, \beta=-.64, t=-7.40, p$ $\leq .001)$. 
Journal of Southeast Asian American Education and Advancement, Vol. 10 [2015], Iss. 1, Art. 7

Lin, Her, Gloria - Understanding the educational experiences of Hmong American undergraduates

Table 1

Descriptives and Correlations for the Study's Variables

\begin{tabular}{|c|c|c|c|c|c|c|c|c|c|c|c|c|c|}
\hline \multirow[b]{2}{*}{ Variable } & \multirow[b]{2}{*}{$M$} & \multirow[b]{2}{*}{$S D$} & \multirow[b]{2}{*}{$\alpha$} & \multicolumn{10}{|c|}{ Correlations } \\
\hline & & & & 2 & 3 & 4 & 5 & 6 & 7 & 8 & 9 & 10 & 11 \\
\hline 1. Perfectionism & 3.06 & .61 & .73 & $-.27^{*}$ & $-.31^{* *}$ & $.31^{* * *}$ & -.12 & -.04 & -.19 & -.15 & $-.32^{* *}$ & $-.23^{*}$ & -.11 \\
\hline 2. Self-esteem & 3.15 & .51 & .86 & & $.45^{* *}$ & $-.65^{* *}$ & .18 & $.33^{* *}$ & $.42^{* *}$ & $.45^{* *}$ & $.53^{* *}$ & $-.27^{*}$ & $.51^{* *}$ \\
\hline 3. Self-efficacy & 4.94 & .89 & .90 & & & $-.52^{* *}$ & $-.22^{* *}$ & $.33^{* *}$ & $.59^{* *}$ & $.37^{* *}$ & $.31^{* *}$ & $.21^{* *}$ & $.43^{* *}$ \\
\hline 4. Phoniness & 3.42 & .76 & .77 & & & & $-.31^{* * *}$ & $-.31^{* *}$ & $-.59^{* *}$ & $-.51^{* *}$ & $-.55^{* *}$ & $-.28^{*}$ & $-.58^{* *}$ \\
\hline 5. Mentoring & 2.77 & .66 & .79 & & & & & .10 & $.31^{* *}$ & $.29^{* *}$ & $.14^{* *}$ & .35 & .21 \\
\hline 6. Encouragement & 3.34 & .57 & .87 & & & & & & $.32^{* *}$ & $.37^{* *}$ & $.28^{*}$ & .14 & $.35^{* *}$ \\
\hline 7. Friend support & 3.66 & .64 & .92 & & & & & & & $.49^{* *}$ & $.39^{* *}$ & .20 & $.55^{* *}$ \\
\hline 8. Identity & 3.19 & .50 & .87 & & & & & & & & $.37^{* *}$ & $.24^{*}$ & $.43^{* *}$ \\
\hline 9. Congruity & 4.87 & .70 & .81 & & & & & & & & & $.51^{* *}$ & $.46^{* *}$ \\
\hline 10. Environment & 4.86 & .93 & .77 & & & & & & & & & & $.48^{* *}$ \\
\hline 11. Persistence & 3.55 & .46 & .80 & & & & & & & & & & \\
\hline
\end{tabular}

Notes. ${ }^{*} p \leq .05,{ }^{* * *} p \leq .01,{ }^{* * *} p \leq .001$.

1. Perfectionism Scale, 2. Rosenberg Self-Esteem Scale, 3. College Self-Efficacy Inventory, 4. Imposter Syndrome Scale, 5. Mentoring Scale, 6. Parental Educational Encouragement Scale, 7. Perceived Social Support InventoryFriends, 8. Ethnic Identity, 9. Cultural Congruency Scale, 10. University Environment Scale, 11.

Persistence/Voluntary Dropout Decisions Scale. 
Lin et al.: Kawm Ntawv Qib Siab Understanding the psychosociocultural educational experiences of Hmong American undergraduates Lin, Her, Gloria - Understanding the educational experiences of Hmong American undergraduates

Table 2

Canonical Covariates for the Study's Variables

\begin{tabular}{|c|c|c|c|c|}
\hline Variable Set & Root $1 \beta$ & $\begin{array}{l}\text { Canonical } \\
\text { Correlation }\end{array}$ & Root $2 \beta$ & $\begin{array}{l}\text { Canonical } \\
\text { Correlation }\end{array}$ \\
\hline Self-beliefs ${ }^{a}$ & $p \leq .001$ & .72 & $p \geq .05$ & .13 \\
\hline Perfectionism & .26 & & -.07 & \\
\hline Self-esteem & -.65 & & -.63 & \\
\hline Self-efficacy & -.88 & & -.11 & \\
\hline Phoniness & .87 & & -.19 & \\
\hline \multicolumn{5}{|l|}{ Social Support } \\
\hline Mentoring & -.40 & & .17 & \\
\hline Encouragement & -.52 & & -.85 & \\
\hline Friend support & -.96 & & .23 & \\
\hline Self-beliefs ${ }^{b}$ & $p<.001$ & .71 & $p<.05$ & .19 \\
\hline Perfectionism & .38 & & .79 & \\
\hline Self-esteem & -.87 & & -.12 & \\
\hline Self-efficacy & -.58 & & .29 & \\
\hline Phoniness & .93 & & -.11 & \\
\hline \multicolumn{5}{|c|}{ University Comfort } \\
\hline Identity & -.77 & & .60 & \\
\hline Congruity & -.86 & & -.49 & \\
\hline Environment & -.43 & & -.49 & \\
\hline Social Support $^{\mathrm{c}}$ & $p \leq .001$ & .66 & $p \leq .05$ & .41 \\
\hline Mentoring & -.46 & & .87 & \\
\hline Encouragement & -.64 & & -.10 & \\
\hline Friend support & -.91 & & -.20 & \\
\hline \multicolumn{5}{|c|}{ University Comfort } \\
\hline Identity & -.91 & & .07 & \\
\hline Congruity & -.72 & & -.16 & \\
\hline Environment & -.45 & & .75 & \\
\hline
\end{tabular}

Notes. Only roots significant at $p \leq .01$ were identified as significant.

${ }^{\mathrm{a}} F=(21,181.45)=3.33, p \leq .001 .{ }^{\mathrm{b}} F=(15,199.16)=4.64, p \leq .001 .{ }^{\mathrm{c}} F=(15,199.16)=4.64, p \leq .001$.

See previous table for key to scales.

\section{Discussion}

Using a psychosociocultural framework to understand the factors influencing students' educational experiences and academic persistence processes (Gloria \& Rodriguez, 2000), this study explored the educational experiences of $85 \mathrm{Hmong}$ undergraduates. Two-thirds of the students were first-generation college students, most of whom $(95.3 \%)$ received educational scholarships. Psychological, social and cultural dimensions were salient to interpret Hmong American students' educational processes, with selfefficacy, imposter feelings, and peer social support, in particular, contributing to this understanding.

Most likely "separated" from their families and communities for the first time, students may have relied more on their peer network than their families for academic support. As first-generation college students, whose families were likely unable to provide academic support given their lack of familiarity or understanding of the higher education system (Sengkhammee et al., 2008; Tang et al., 2013), self-beliefs and social support from friends took a more prominent role than family in the study's findings. Similar to previous research (Gloria \& Ho, 2001; Steinberg, Dornbusch, \& Brown, 1992), the influences of 
confidence in oneself and ability to succeed as well as a support system from friends were prominent for Hmong American undergraduates. Specifically, decreased perception of support from friends was related to a lower sense of confidence in their ability to complete college-related tasks along with lower selfesteem and higher imposter feelings. As many of the study's participants were recruited through Hmong student campus organization, it is likely that social connections and mentorship from fellow Hmong American undergraduates served as a means of academic success (Swartz et al., 2003) and educational encouragement.

In addition, decreased support from friends and family and lower self-beliefs were related to lower ethnic identity and cultural incongruity between self and the academic environment. As most participants were affiliated with Hmong student organization, they were likely encouraged to identify with their Hmong culture and maintain familial cultural values within the academic environment. As a result, they may (a) establish trusting supportive relationships with these ethnically-similar peers who buffer the impact of incongruent cultural values and (b) believe they are capable of succeeding despite feeling unwelcomed and alienated in their educational context. For students who recently immigrated from Southeast Asia, having a safe place where familial cultural values are shared is important (Tang et al., 2013), especially if faculty and staff are not familiar and integrative of Hmong values.

By class standing, upper-division students reported higher college self-efficacy and perceived social support from friends than did lower division students. Having spent more time at the university, upper division students indicated an increased sense of confidence in their ability to complete successfully college-related academic tasks - a finding consistent with self-efficacy theory (Bandura, 1986) and college self-efficacy research on students of color (Hurtado \& Carter, 1997). Perhaps as a function of feeling more confident and supported by friends, these Hmong American undergraduates may have used networking or building relationships as coping strategies to help them persist in the perceived challenging academic environment, a similar process used by other racial and ethnic minority students (DelgadoRomero \& Hernandez, 2002).

Although navigating the educational system and strengthening their peer support networks the longer they were in school, the upper-division Hmong American undergraduates perceived the environment as more unwelcoming and culturally incongruent than their lower-division counterparts, findings similar to Sengkhammee et al.'s research (2008). That is, over time upper-division students may have experienced increased racial discrimination (Fuertes et al., 1994), more accurately assessed the degree to which they were valued as an ethnic group, or identified differences in their cultural values and those of the university. Yet simultaneously, an overall decreased perception of cultural incongruity between self and the university environment for the study's Hmong American undergraduates was related to a lower sense of self-esteem and confidence, underscoring the potential impact of the sociocultural context on students' psychological and educational processes (Gloria \& Rodriguez, 2000).

A salient self-belief that emerged from the study's finding was that Hmong American students' sense of intellectual phoniness was the strongest predictor of academic persistence. Despite the students doing well academically (i.e., 2.95 grade point average), an increase in feelings of phoniness was related to decreased academic persistence decisions. Given the university context and climate for students of color, and Asian American students specifically, it is feasible that they experienced negative and stereotypical messages from campus (e.g., faculty and peers) (Cokley et al., 2012; Ong, Burrow, FullerRowell, Ja, \& Sue, 2013). Further, popular media and literature reinforces a "model minority" image of Asian Americans as educationally successful and "problem-free" (Suzuki, 2002). The study's Hmong American students may have felt pressure to uphold an even greater level of academic prowess consistent with a model minority stereotype, and in turn questioned their intellectual ability and subsequent welcome or belonging on campus. Their imposter feelings may have also stemmed from familial pressures (King \& 
Cooley, 1995; Supple et al., 2010), as families and communities encourage them to stabilize, advance (Lee, 1997), and propel others economically and socially (Hutchinson, 1997) via higher education. Such familial perceived pressures and assumed responsibilities, which have been associated with increased anxiety and stress (King \& Cooley, 1995), may nonetheless result in students' perceived uncertainty, despite their academic capabilities, to persist academically.

Perhaps most surprising was the limited role that perceived parental encouragement had within the interrelationships of the study's variables. Counter to research in which Hmong families (and specifically parents) had a significant influence on their children's educational pursuits (Her \& Gloria, 2015; Hutchinson, 1997; Lor, 2008; Supple et al., 2010), lower perceived parental encouragement was associated with cultural factors (i.e., lower ethnic identity and cultural incongruity), yet not related to students' self-beliefs. Understandably, the perception of parental encouragement can simultaneously increase one's confidence and engender concern or doubt, yet the encouragement may not have included the specific academic-related information needed for the students to negotiate educational challenges and ultimately make informed decisions about their academic persistence (Her \& Gloria, 2015). Although the degree that parents were aware of their children's academic experiences was not assessed, questions emerge as to whether Hmong parents have knowledge of (a) how the American higher education system functions, (b) their children's academic demands, (c) their students' experience of culture shock, and (d) the subsequent impact of an unwelcoming university environment on their general well-being. Given that parents and family members are often identified as the most influential people in students' educational pursuits and goals (Lor, 2008; Supple et al., 2010; Swartz et al., 2003), it is clear that more research is needed to support or refute this study's findings, as well as to determine the nuances of parents' roles within the educational process of their undergraduates.

Finally, females reported higher perception of peer social support than males, the only significant finding by gender. Of the research with Hmong undergraduates, Lee (1997) reported that Hmong females are more assertive and active college students than Hmong males. By pursuing higher education, young Hmong women challenge the traditional values of a patriarchal culture and notions of early marriage and motherhood to gain independence (Lee, 1997). As this study did not specifically examine traditional gender roles, research which explores the proximal issues underlying gender difference in Hmong American undergraduates' educational experiences and persistence decisions is warranted.

\section{Implications of Study Findings}

The study's findings have multiple direct implications for college campuses to best support the educational experiences and persistence of Hmong American undergraduates. These implications were addressed through the Psychosociocultural framework (Gloria \& Rodriguez, 2000) and indicators from the Culturally Engaging Campus Environment Model (Museus, 2014) to assist in educational success. First, to ensure cultural familiarity (Museus, 2014) and opportunity to have social connections (Gloria \& Rodriguez, 2000), universities would do well to support Hmong-specific student organizations by allowing them the opportunity to physically, socially, and culturally connect with others with whom they share congruent backgrounds and values (e.g., group emphasis orientation). Hmong American and others racially diverse students who are numerically under-represented on campus and/or are newer to the academic environment (i.e., first-generation college, immigrant, lower socioeconomic status) could benefit from engaging with peers who are experiencing similar educational challenges.

Second, these findings emphasize the significance of cultivating holistic and integrative support through formal and informal relationships (Gloria \& Rodriguez, 2000; Museus, 2014) to counteract imposter feelings. Universities would do well to increase the number of Hmong faculty, administrators, 
and academic staff (e.g., student advisors) to provide a stronger academic mentoring community beyond family and peers (Museus \& Neville, 2012). Allowing Hmong students to engage in relationships that are congruent to their values and worldviews as well as allow them to learn from other experiences could decrease students' sense of intellectual phoniness. For example, if a Hmong advisor or faculty member shared their cultural narrative and successful management of educational challenges with a Hmong undergraduate, the student may feel that they could similarly achieve academic success.

Finally, all university personnel should gain more knowledge and understanding of the needs and values of the fast-growing Hmong American student population to ensure culturally-competent learning spaces (e.g., classroom) and culturally-validating environments (Gloria \& Rodriguez, 2000; Museus, 2014). Having validating spaces for Hmong American undergraduates could ultimately allow them a greater sense of belonging, mattering, and propensity for educational success.

\section{Study Limitations and Future Research Directions}

Several of the study's limitations should be considered in light of the findings. Using a cross-sectional approach and nonrandom sampling method, generalizability of the study's finding to Hmong American students attending other university settings should be made with caution. Although a relatively small sample size was secured, which may have affected the power of the study's analysis, almost one-third of the Hmong American undergraduate population on campus participated in the study, which nonetheless yielded significant differences. Despite the smaller sample size, the canonical correlations were strong: .66 to .72, and yielded significant relationships. Further, only the first significant root was interpreted to ensure reliable interpretation of findings (Steven, 1986). Given their low representation on campus, future research would do well to collaborate with university administrators to identify the entire Hmong American undergraduate population potentially available for study inclusion.

Next, that data was collected primarily from Hmong student organization sponsored events, the ethnic identity of the participants may have been stronger than those who did not attend events nor participate in the study. Similarly, the degree to which participants may have perceived stronger peer support (especially from ethnically-similar peers experiencing comparable struggles) may have influenced their educational experiences differently than those not associated with Hmong-specific student organizations. Given the significant role that student organizations play for minority students in creating family and providing socio-emotional support (Delgado-Romero \& Hernandez, 2002), future studies should explore their influence on Hmong American students' educational experiences and ultimate academic persistence.

Furthermore, the majority of the study's Hmong American students received some form of financial aid and university scholarship. A question emerges as to whether this study's sample had an overrepresentation of Hmong American undergraduates who were affiliated with some form of federallyfunded programming (i.e., are of low-income background) or if the majority of Hmong American students at the university at which the study was conducted received some form of funding in order to attend school. Nonetheless, finances play an important role in students' educational experiences (Carter, 2006) and likely influenced their educational experiences (Xiong \& Lee, 2011). For example, research indicated that Hmong American undergraduates reported lack of finances as the largest obstacle in their educational pursuits (Xiong \& Lee, 2015; Vang, 2015). For this current study, the role of finances was not addressed and more importantly how students and their families experienced financial stress and strains and resulting influence on their pragmatic ability to persistence in higher education (i.e., pay for college; Huffcutt, 2010) was not explored. Future studies would do well to examine how financial stress and strain 
for Hmong American students continue to be a prominent factor despite receiving financial assistance (Vang, 2015) and subsequently influence their educational experience.

Although the study's measures were generally created and validated for and with racial and ethnic samples, additional research is needed to expand on the educational constructs and verify their utility with Hmong American undergraduates. For example, despite adequate internal consistency, the Parental Educational Encouragement Scale may not have captured parents' educational encouragement. Given that educational encouragement often includes family members beyond their parents (e.g. grandparents, aunts, uncles, and siblings) and involves pressures to advance the family (Swartz et al., 2003), this scale may not have fully tapped the cultural and contextual nuances of parental encouragement experienced by immigrant, first-generation college students. Ultimately, in-depth explorations and longitudinal studies of Hmong American students' educational experiences can increase persistence and retention rates and direct university personnel to provide culturally-contextualized student programming that ensures students' personal and academic well-being and success. With the paucity of research on Hmong American undergraduates, quantitatively-focused, theoretically-grounded, and interdisciplinary studies which address their educational needs and processes can direct a much needed line of inquiry.

\section{References}

Bandura, A. (1986). Social foundations of thought and action: A social cognitive theory. Englewood Cliffs, NJ: Prentice Hall.

Burns, D. D. (1980). The perfectionist's script for self-defeat. Psychology Today, 34-52.

Canon, H. J. (1996). Ethical standards and principles. In S. R. Komives, D. B. Woodard, Jr., \& Associates (Eds.), Student services: A handbook for the profession (3rd ed.) (pp. 106-125). San Francisco, CA: Jossey-Bass.

Carter, D. F. (2006). Key issues in the persistence of underrepresented minority students. New Directions for Institutional Research, 2006(130), 33-46. doi: 10.1002/ir.178

Castellanos, J., \& Gloria, A. M. (2007). Research considerations and theoretical applications for best practices in higher education: Latina/os achieving success. Journal of Hispanic Higher Education, 6(4), 378-396. doi: 10.1177/1538192707305347

Castellanos, J., Gloria, A. M., \& Kamimura, M. (Eds.). (2006). The Latina/o pathway to the Ph.D.: Abriendo Caminos. Sterling, VA: Stylus.

Chang, M. J. (2003). Racial differences in viewpoints about contemporary issues among entering college students: Fact or fiction? Journal of Student Affairs Research and Practice, 40(4), 587-603. doi: $10.2202 / 1949-6605.1280$

Chiang, A., Fisher, J., Collins, W., \& Ting, M. (2015). (Mis)labeled: The challenge of academic capital formation for Hmong American high school students in an urban setting. Journal of Southeast Asian American Education and Advancement, 10(1), 1-32. doi:10.7771/2153-8999.1118

Clance, P. R., \& Imes, S. A. (1978). The imposter phenomenon in high achieving women: Dynamics and therapeutic intervention. Psychotherapy: Theory, Research \& Practice, 15(3), 241-247. doi: $10.1037 / \mathrm{h} 0086006$

Cokley, K., McLain, S., Enciso, A., \& Martinez, M. (2012). An examination of the impact of minority stress and impostor feelings on the mental health of diverse ethnic minority college students. Journal of Multicultural Counseling and Development, 41(2), 82-95. doi: 10.1002/j.21611912.2013.00029.x 
Lin, Her, Gloria - Understanding the educational experiences of Hmong American undergraduates

Cole, D. A., Maxwell, S. E., Arvey, R., \& Salas, E. (1993). Multivariate group comparisons of variable systems: MANOVA and structural equation modeling. Psychological Bulletin, 114(1), 174-184. doi: 10.1037/0033-2909.114.1.174

Delgado-Romero, E., \& Hernandez, C. (2002). Empowering Hispanic students through student organizations: Competencies for faculty advisors. Journal of Hispanic Higher Education, 1(2), 144-157. doi: 10.1177/1538192702001002004

Fass, M., \& Tubman, J. (2002). The influence of parental and peer attachment on college students' academic achievement. Psychology in the Schools, 39(5), 561-574. doi: 10.1002/pits.10050

Fuertes, J. N., Sedlacek, W. E., \& Liu, W. M. (1994). Using the SAT and noncognitive variables to predict the grades and retention of Asian American university students. Measurement and Evaluation in Counseling and Development, 27(2), 74-84.

Gloria, A. M., Castellanos, J., \& Orozco, V. (2005). Perceived educational barriers, cultural congruity, coping responses, and psychological well-being of Latina undergraduates. Hispanic Journal of Behavioral Sciences, 27(2), 161-183. doi: 10.1177/0739986305275097

Gloria, A. M., Hird, J. S., \& Navarro, R. L. (2001). Relationships of cultural congruity and perceptions of the university environment to help-seeking attitudes by sociorace and gender. Journal of College Student Development, 42(6), 545-562.

Gloria, A. M., \& Ho, T. A. (2003). Environmental, social, and psychological experience of Asian American undergraduates: Examining issues of academic persistence. Journal of Counseling and Development, 81(1), 93-105. doi: 10.1002/j.1556-6678.2003.tb00230.x

Gloria, A., \& Robinson Kurpius, S. E. (1996). The validation of the Cultural Congruity Scale and the University Environment Scale with Chicano/a students. Hispanic Journal of Behavioral Sciences, 18(4), 533-549. doi: 10.1177/07399863960184007

Gloria, A. M., Robinson Kurpius, S. E., Hamilton, K. D. \& Willson, M. S. (1999). African American academic nonpersistence at a predominantly White institution: Issues of social support, university comfort, and self-beliefs. Journal of College Student Development, 40(3), 257-268.

Gloria, A. M., \& Rodriguez, E. R. (2000). Counseling Latino university students: Psychosociocultural issues for consideration. Journal of Counseling \& Development, 78(2), 145-154. doi: 10.1002/j.1556-6676.2000.tb02572.x

Harris, R. J. (1985). A primer of multivariate statistics (2nd ed.). San Diego: CA: Academic Press.

Harvey, J. C. (1982). The imposter phenomenon and achievement: A failure to internalize success (Doctoral dissertation, Temple University, 1981). Dissertation Abstracts International, 42, 4969B4970B.

Her, P., \& Gloria, A. M. (2015). Kev txhawb siab: Hmong parents' educational encouragement of their undergraduate daughter/son. Manuscript submitted for publication.

House, J. D. (1997). The relationship between self-beliefs, academic background, and achievement of adolescent Asian-American students. Child Study Journal, 27(2), 95-110.

Hsia, J., \& Hirano-Nakanishi, M. (1996). The demographics of diversity: Asian Americans in higher education. In C. Turner, M. Garcia, A. Nora, \& L. I. Rendon (Eds.), Racial and ethnic diversity in higher education (pp. 241-246). Needham Heights, MA: Simon \& Schuster.

Huffcutt, M. (2010). American Hmong youth and college readiness: Integrating culture and educational success (Unpublished Master's thesis). University of Wisconsin-Stout, Menomonie, WI.

Hurtado, S., \& Carter, D. F. (1997). Effects of college transition and perceptions of the campus racial climate on Latino college students' sense of belonging. Sociology of Education, 70(4), 324-345. Doi: $10.2307 / 2673270$ 
Lin et al.: Kawm Ntawv Qib Siab Understanding the psychosociocultural educational experiences of Hmong American undergraduates

Lin, Her, Gloria - Understanding the educational experiences of Hmong American undergraduates

Hurtado, S. (1994). The institutional climate for talented Latino students. Research in Higher Education, 35(1), 21-41. doi: 10.1007/BF02496660

Hutchinson, R. (1997). The educational performance of Hmong students in Wisconsin. Wisconsin Policy Research Institute.

Kim, B. S. K., \& Omizo, M. M. (2005). Asian and European American cultural values, collective selfesteem, acculturative stress, cognitive flexibility, and self-efficacy among Asian American college students. Journal of Counseling Psychology, 52(3), 412-419. doi: 10.1037/0022-0167.52.3.412

King, J. E., \& Cooley, E. L. (1995). Achievement orientation and the impostor phenomenon with college students. Contemporary Educational Psychology, 20(3), 304-312. doi: 10.1016/j.paid.2005.05.014

Langford, J., \& Clance, P. R. (1993). The imposter phenomenon: Recent research findings regarding dynamics, personality and family patterns and their implications for treatment. Psychotherapy, 30(3), 495-501. doi: 10.1037/0033-3204.30.3.495

Lee, R. M., \& Davis, C. (2000). Cultural orientation, past multicultural experience, and a sense of belonging on campus for Asian American college students. Journal of College Student Development, 41(1), 110-115.

Lee, R. M., \& Yoo, H. C. (2004). Structure and measurement of ethnic identity for Asian American college students. Journal of Counseling Psychology, 51(2), 263-269. doi: 10.1037/00220167.51.2.263

Lee, S. C. (2007). The self-rated social well-being of Hmong college students in Northern California, Hmong Studies Journal, 8(1), 1-19.

Lee, S. J. (2001). More than "model minorities" or "delinquents:" A look at Hmong American high school students. Harvard Educational Review, 71(3), 505-528.

Lee, S. J. (1997). The road to college: Hmong American women's pursuit of higher education. Harvard Educational Review, 67(4), 803-827.

Lor, P. (2008). Key life experiences contributing to Hmong students' matriculation. Multicultural Education, 16(1), 39-47.

McNall, M., Dunnigan, T., \& Mortimer, J. (1994). The educational achievement of the St. Paul Hmong. Anthropology and Educational Quarterly, 25(1), 44-65. doi: 10.1525/aeq.1994.25.1.05x0965c

Millett, S. (2002). The Hmong of Southeast Asia: First Peoples. Minneapolis, MN: Learner Publications.

Moua, T. (2003). The Hmong culture: Kinship, marriage, \& family systems. Unpublished master's thesis, University of Wisconsin-Stout, Menomonie, WI.

Museus, S. D. (2014). The Culturally Engaging Campus Environments (CECE) Model: A new theory of success among racially diverse college student populations. In M. B. Paulsen (Ed.), Higher education: Handbook of theory and research (pp. 189-227). New York, NY: Springer Science.

Museus, S. D., \& Neville, K. M. (2012). Delineating the ways that key institutional agents provide racial minority students with access to social capital in college. Journal of College Student Development, 53(3), 436-452. doi: 10.1353/csd.2012.0042

Ngo, B. (2002). Contesting "culture": The perspectives of Hmong American female students on early marriage. Anthropology \& Education Quarterly, 33(2), 163-188. doi: 10.1525/aeq.2002.33.2.163

Ong, A. D., Burrow, A. L., Fuller-Rowell, T. E., Ja, N. M., \& Sue, D. W. (2013). Racial microaggressions and daily well-being among Asian Americans. Journal of Counseling Psychology, 60(2), 188-199. doi.org/10.1037/a0031736

Pascarella, E. T., \& Terenzini, P. T. (1980). Predicting freshman persistence and voluntary dropout decisions from a theoretical model. Journal of Higher Education, 51(1), 60-75. doi: $10.2307 / 1981125$ 
Lin, Her, Gloria - Understanding the educational experiences of Hmong American undergraduates

Phinney, J. S. (1992). The multigroup ethnic identity measure: A new scale for use with diverse groups. Journal of Adolescent Research, 7(2), 156-176. doi: 10.1177/074355489272003

Procidano, M. E., \& Heller, K. (1983). Measures of perceived social support from friends and from family: Three validation studies. American Journal of Community Psychology, 11(1), 1-24. doi: 10.1007/bf00898416

Rankin, S., \& Reason, R. (2005). Differing perceptions: How students of color and white students perceive campus climate for underrepresented groups. Journal of College Student Development, 46(1), 43-61. doi: 10.1353/csd.2005.0008

Reeves, T. J., \& Bennett, C. E. (2004). We the people: Asians in the United States. (Census 2000 Special Reports, CENSR-17). Washington, DC: U.S. Census Bureau.

Rosenberg, M. (1965). Society and the adolescent self-image. Princeton, NJ: Princeton University Press.

Ross, S. R., Stewart, J., Mugge, M., \& Fultz, B. (2001). The imposter phenomenon, achievement dispositions, and the five factor model. Personality and Individual Differences, 31(8), 1347-1355. doi: 10.1016/s0191-8869(00)00228-2

Sengkhammee, J, T., Gloria, A. M., Her, P., Lin, M. M., Thao, B. J., Cabinte, D., \& Aroonsavath, L. (2008). Txoj Kev Nsthiab: Understanding Hmong American undergraduates educational experiences. Paper presented at the 2008 Annual American Psychological Conference, Boston, MA.

Solberg, V. S., O’Brien, K., Villareal, P., Kennel, R., \& Davis, B. (1993). Self-efficacy and Hispanic college students: Validation of the College Self-Efficacy Inventory. Hispanic Journal of the Behavioral Sciences, 15(1), 80-95. doi: 10.1177/07399863930151004

Steinberg, L., Dornbusch, S., \& Brown, B. B. (1992). Ethnic differences in adolescent achievement. American Psychologist, 47(6), 723-729. doi: 10.1037//0003-066x.47.6.723

Stevens, J. (1986). Applied multivariate statistics in social science. Hillsdale, NJ: Earlbaum Publishers.

Su, J., Lee, R. M., \& Vang, S. (2005). Intergenerational family conflict and coping among Hmong American college students. Journal of Counseling Psychology, 52(4), 482-489. doi:10.1037/00220167.52.4.482

Sue, D. W., \& Sue, D. (2009). Counseling the culturally different: Theory and practice (5th Ed.). San Francisco, CA: Wiley.

Sumi, K., \& Kanda, K. (2002). Relationship between neurotic perfectionism, depression, anxiety, and psychosomatic symptoms: A prospective study among Japanese men. Personality and Individual Differences, 32(5), 817-826. doi: 10.1016/s0191-8869(01)00088-5

Supple, A. J., McCoy, S. Z., \& Wang, Y. (2010). Parental influences on Hmong university students' success. Hmong Studies Journal, 11(1), 1-37.

Suzuki, B. H. (Spring 2002). Revisiting the model minority stereotype: Implications for student affairs practice and higher education. New Directions for Student Services, 2002 (97), 21-32. doi: $10.1002 /$ ss. 36

Suzuki, B. H. (1994). Higher education issues in the Asian American community. In M. J. Justiz, R. Wilson, \& L. G. Björk (Eds.), Minorities in higher education (pp. 258-285). Phoenix, AZ: Oryx Press.

Swartz, T., Lee, J. C., \& Mortimer, J. T. (2003). Achievements of first-generation Hmong youth: Findings from the Youth Development Survey. CURA Reporter, 33, 15-21.

Tang, J., Kim, S., \& Haviland, D. (2013). Role of family, culture, and peers in the success of firstgeneration Cambodian American college students. Journal of Southeast Asian American Education \& Advancement, 8(1). doi: 10.7771/2153-8999.1057 
Thompson, B. (1995). Stepwise regression and stepwise discriminant analysis need not apply here: A guidelines editorial. Educational and Psychological Measurement, 55(4), 525-534. doi: $10.1177 / 0013164495055004001$

Torres, V., \& Hernandez, E. (2007). The influence of ethnic identity on self-authorship: A longitudinal study of Latino/a. Journal of College Student Development, 48(5), 558-573. doi: $10.1353 /$ csd.2007.0057

U.S. Census Bureau. (2013). American Community Survey: Selected racelancestry. Retrieved from http://factfinder2.census.gov/faces/tableservices/jsf/pages/productview.xhtml?pid= ACS_13_1YR_S0201\&prodType=table

Weiss, D. J. (1972). Canonical correlation analysis in counseling psychology research. Journal of Counseling Psychology, 19(3), 241-252. doi: 10.1037/h0032675

Xiong, S., \& Lam, S. K. (2013). Factors affecting the success of Hmong college students in America. British Journal of Guidance \& Counselling, 41(2), 132-144. doi: 10.1080/03069885.2012.713909

Xiong, S., \& Lee, S. E. (2011). Hmong students in higher education and academic support programs. Hmong Studies Journal, 12(1), 1-20.

Xiong, Y. S. (2012). Hmong Americans' educational attainment: Recent changes and remaining challenges. Hmong Studies Journal, 13(2), 1-8.

Vang, F. (2015). Barriers that impact Hmong students in post-secondary education. Master of Social Work Clinical Research Papers, Paper 531. Retrieved from http://sophia.stkate.edu/mw_papers/531 


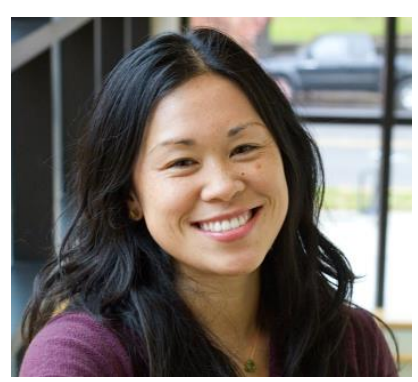

Mariko M. Lin is a senior staff psychologist and the Education and Prevention Outreach Director at the University of Oregon's Counseling \&Testing Center. Her clinical and research interests focus on the persistence and retention of underrepresented students from diverse backgrounds especially racial/ethnic minority students and first-generation college students.

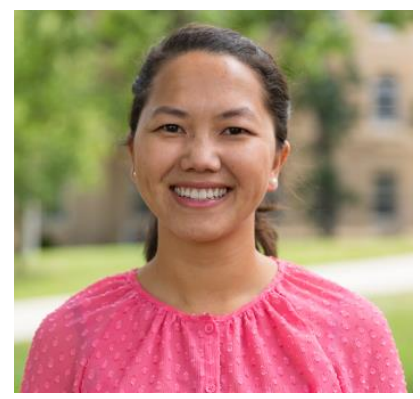

$\mathrm{Pa}$ Her is a doctoral student in the Department of Counseling Psychology at the University of Wisconsin-Madison. Her research examines the educational experiences of Hmong American students in higher education and the career development of racial ethnic minority individuals.

Alberta M. Gloria is a Professor in the Department of Counseling Psychology at the University of Wisconsin-Madison. Her research focuses on a Psychosociocultural understanding of the educational processes and coping strategies that facilitate academic persistence and educational wellness for students of color in higher education. 


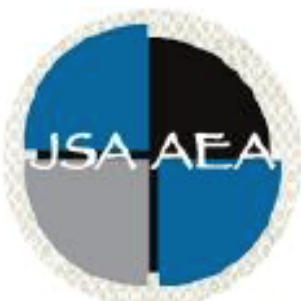

Vol. 10 (2015)

\section{Journal of Southeast Asian American Education and Advancement}

www.JSAAEA.org

\section{Editor}

Dr. Wayne E. Wright

Purdue University

Associate Editors

Dr. Chhany Sak-Humphry

University of Hawaii at Manoa

Dr. Phitsamay Sychitkokhong Uy

University of Massachusetts, Lowell

\section{Book Review Editor}

Dr. Vichet Chhuon

University of Minnesota

\section{Creative Works Editor}

Bryan Thao Worra

Lao Assistance Center

\section{Journal Manager \\ Marshall Klassen \\ Purdue University}

\section{Editorial Review Board}

Dr. Steve Arounsack

California State University, Stanislaus

Dr. Sovicheth Boun

The State University of New York at Fredonia

Dr. George Chigas

University of Massachusetts, Lowell

Dr. Hien Duc Do

San Jose State University

Dr. Sophal Ear

Occidental College

Dr. Jeremy Hein

University of Wisconsin, Eau Claire

Dr. Nancy H. Hornberger

University of Pennsylvania

Dr. Peter Nien-Chu Kiang

University of Massachusetts, Boston
Dr. Carl L. Bankston III

Tulane University

Dr. Phala Chea

Lowell Public Schools

Dr. Loan Dao

University of Massachusetts, Boston

Dr. Changming Duan

University of Missouri, Kansas City

Dr. Sothy Eng

Lehigh University

Dr. Vincent K. Her

University of Wisconsin, Eau Claire

Dr. Peter Tan Keo

New York University

Dr. Kevin K. Kumashiro

University of San Francisco 


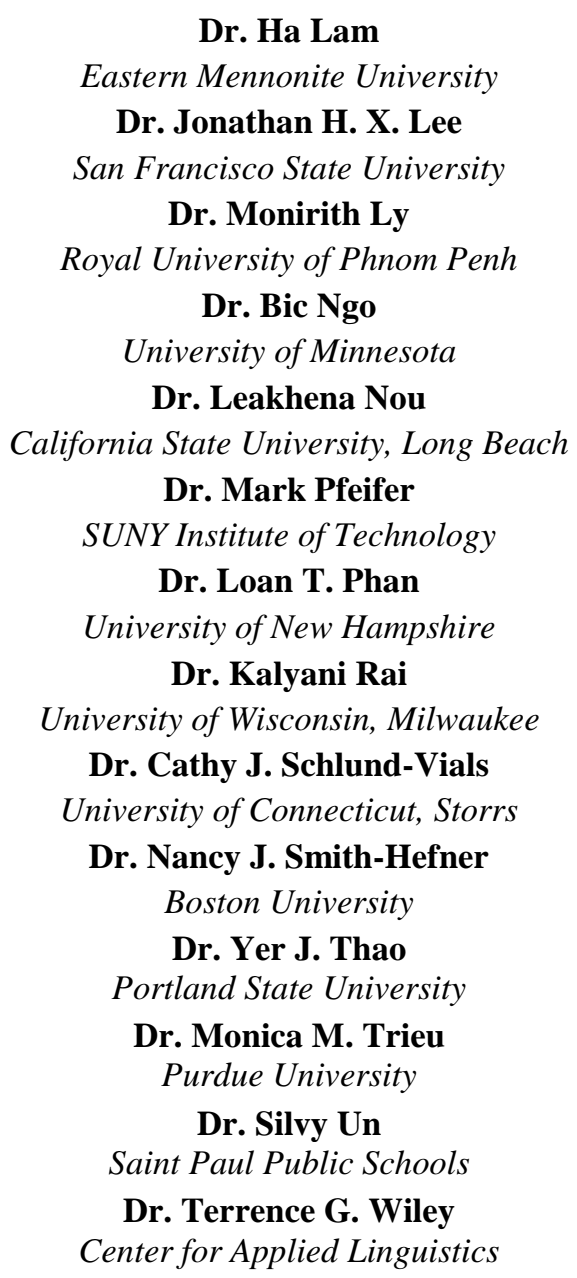

\author{
Dr. Ravy Lao \\ California State University, Los Angeles \\ Dr. Stacey Lee \\ University of Wisconsin, Madison \\ Dr. Sue Needham \\ California State University, Dominguez Hills \\ Dr. Max Niedzwiecki \\ Daylight Consulting Group \\ Dr. Clara Park \\ California State University, Northridge \\ Dr. Giang Pham \\ University of Massachusetts \\ Dr. Karen Quintiliani \\ California State University, Long Beach \\ Dr. Angela Reyes \\ Hunter College, The City University of New York \\ Dr. Fay Shin \\ California State University, Long Beach \\ Dr. Christine Su \\ Ohio University \\ Dr. Alisia Tran \\ Arizona State University \\ Dr. Khatharya Um \\ University of California, Berkeley \\ Dr. Linda Trinh Vo \\ University of California, Irvine \\ Dr. Yang Sao Xiong \\ University of Wisconsin-Madison
}

Dr. Zha Blong Xiong

University of Minnesota

\section{Doctoral Student Editorial Review Board}

\author{
Virak Chan \\ University of Texas at San Antonio \\ Annie BichLoan Duong \\ San Joaquin County Office of Education \\ Hoa Nha Nguyen \\ Boston College \\ Malaphone Phommasa \\ Marshall University \\ Molly Wiebie \\ The University of Texas at Austin
}

\author{
Keo Chea-Young \\ University of Pennsylvania \\ Dung Minh Mao \\ University of Minnesota \\ Thien-Huong Ninh \\ University of Southern California \\ Krissyvan Truong \\ Claremont Graduate University \\ Soua Xiong \\ San Diego State University \& \\ Claremont Graduate University
}

Anna H. Yang

University of Georgia 